\title{
Food Insecurity and Associated Factors Among Households in Areka Town, Southern Ethiopia
}

\author{
Habte Samuel $^{1} \quad$ Gudina Egata $^{2} \quad$ Wondimagegn Paulos $^{3} \quad$ TesfahunYonas Bogale $^{4} \quad$ Minyahil Tadesse $^{5}$ \\ 1. Maternal and child health \& nutrition service core process, Regional Health Bureau, Southern nations, \\ nationalities and people, Ethiopia \\ 2. Public Health, College of Health and Medical Sciences, Haramaya University, Ethiopia \\ 3. Academic Director, School of Public Health, Wolaita Sodo University, Ethiopia \\ 4. Health Sciences and Medicine College, Wolaita Sodo University, Ethiopia \\ 5. Armauer Hansen Research Institute, Ministry of Health, Ethiopia
}

\begin{abstract}
Background: Food insecurity among poor urban households in low income settings is a major public health concern. This study aimed to assess the magnitude of food insecurity and associated factors among households in Areka town, Southern Ethiopia.

Methods: A community based cross-sectional survey was conducted among a total random sample of 309 urban households in Areka town, Southern Ethiopia, from March to April, 2015. Data was gathered using an interviewer administered and pre-tested structured questionnaire. The data was entered into Epi Info version 3.5.3 and exported to SPSS version 20.0 for analysis. Binary logistic regression analysis was used to assess the association between independent and outcome variable. Multivariable analysis was used to identify factors associated with household food insecurity after controlling possible confounders and statistical significance set at $\mathrm{p}$ - value $<0.05$.

Result: The magnitude of household food insecurity was $69.6 \%(95 \% \mathrm{CI}=64.1,75.2)$. Household food insecurity severity status was categorized as mild for $34.3 \%,(95 \% \mathrm{CI}=(29.4,39.8)]$, moderate for $31.7 \%,(95 \% \mathrm{CI}=(26.1$, $37.0)]$, and severe for $3.6 \%,(95 \% \mathrm{CI}=(1.9,5.8)]$ households respectively. Being a poor household [ $(\mathrm{AOR}=3.13$, $95 \% \mathrm{CI}=(1.42,6.91)]$, lack of formal education among household heads $[(\mathrm{AOR}=4.70,95 \% \mathrm{CI}=(1.82,12.12)]$, households whose monthly food expenditure was $<500 \mathrm{ETB}$ [ $(\mathrm{AOR}=6.9,95 \% \mathrm{CI}=1.45,32.9)]$ and between 500- 1500 ETB $[(\mathrm{AOR}=2.70,95 \% \mathrm{CI}=1.48,4.91)]$, and household head's age $\geq 50$ years $[(\mathrm{AOR}=2.11,95 \%$ $\mathrm{CI}=(1.12,3.95)]$ were significantly associated with urban household food insecurity.

Conclusion: The prevalence of urban household food insecurity was high in the study setting. The older age group and lack of formal education by head of the household, household poverty and less monthly household expenditure for food consumption was factors that significantly contributed to urban food insecurity. Therefore, an integrated feasible urban food security interventions should be emphasized at all levels by all relevant stakeholders targeting the urban poor households to ensure urban household food security.
\end{abstract}

Keywords: Areka town, Southern Ethiopia, Household Food insecurity.

DOI: $10.7176 / \mathrm{JHMN} / 66-05$

Publication date:September $30^{\text {th }} 2019$

\section{Background}

Food security is a situation that exists when all people, at all times, have physical, social and economic access to sufficient, safe and nutritious food that meets their dietary needs and food preferences for an active and healthy life [1]. Food security is complex and its drivers are interdependent, such that sufficiency of food alone cannot be a guarantee to food security. Socio-economic, demographic and environmental factors can alter food accessibility in varying degrees [2].Since most low-income groups in urban areas are net buyers of food, access and affordability are central concerns for household food security [3].

Based on Food and Agricultural Organization (FAO) estimates, 842 million of the global population was unable to meet their dietary energy requirements in 2011-2013. Majority of them (98\%) live in developing regions. Many parts of the developing world such as Southern Asia, Sub-Saharan Africa (SSA) and Eastern Asia were food insecure [4]. Food insecurity remains a danger in parts of South and South-east Asia. Food insecurity is a chronic problem and highly prevalent in SSA[2].

In Ethiopia, similar to other developing countries, food insecurity is a major public health agendum. An interim report on poverty analysis survey in 2010/2011 indicated that more than one third of the population of the country was food insufficient [5]. Moreover, FAO estimated that about 32.1 million people (37.1\% of the total population) in the country were undernourished in the years 2011-2013 [4].

Urban food security is gaining particular attention since achieving national food security is one of the keys for sustainable economic development and poverty reduction in the country[5].Available evidence showed that the prevalence of urban food insecurity ranged from $58.2 \%$ to $75 \%$ [6-7]. Some studies also revealed that dependency on markets for food availability with good supply, purchasing power (household income and market prices), access to safe drinking water, sanitation and health facilities were among some important factors 
associated with urban food insecurity in Ethiopia [8]. In addition, educational status of head of the household regardless of sex of the household head, number of earning members in the household, household size, farm size, off farm income, credit access, and marital status also play a role in household food insecurity [9-10].

Although various studies have been conducted to assess the magnitude of rural food insecurity, literature is limited on the urban household food insecurity in Ethiopia. Since urban food insecurity threatens sustainable economic development and poverty reduction, its correlates should be explored further for policy directions. There is also a need for more concern to urban food security due to alarming population growth in urban centers. Furthermore, evidence on urban household food insecurity is essential to design effective food security interventions .Thus, the study was aimed at assessing the prevalence of urban household food insecurity and associated factors in the study setting.

\section{Methods \\ Study area and setting}

The study was conducted from March to April 2015in Areka town, Southern Ethiopia, which is located 299 KM from Addis Ababa, the capital city of Ethiopia [11- 12].

All households found in the study area during the commencement of the study were eligible to be involved in the study.

\section{Sample size and sampling procedures}

A sample size was obtained from a total random sample of309 household heads distributed in the four administrative units of the town. Each administrative unit is further stratified into sub-administrative units. There are $27 \mathrm{sub}$-administrative units in the town of which a total of 9 were selected by simple random sampling technique. A systematic sampling method was used to select the study participants who were eligible for the study. The estimated sample size was proportionally allocated to the selected sub-administrative units based on their population size.

\section{Data collection}

Data were collected using interviewer administered pretested structured questionnaires which was adapted from Food and Agriculture Technical Assistance (FANTA) Version 3(2007) for collecting socio-demographic and Economic details, and household food insecurity access scale (HFIAS) questions. Nine HFIAS questions were used in estimating the prevalence of food insecurity [13]. The questionnaire was first drafted in English language and then translated to Amharic language. Prior to data collection, the purpose of this study was explained to the study participants, their consent to participate was sought and was also informed that their participation in the study was totally voluntary. A total of nine diploma nurses who had prior experience in data collection and proficient in the local language collected data.

The data collectors read out the questions loud and afterwards recorded the responses from the study subjects.

\section{Data collectors and Measurements}

The questionnaires were administered by nine trained and experienced data collectors. Three qualified public health officers supervised the process of data collection. Household food insecurity was measured on the following question items: Presence of worry about food, inability to eat preferred foods, eating monotonous or undesired foods, reduction in meal size and number, not having any foods and going hungry to bed at night or the whole day directed to the households the last four weeks prior to the survey. It was measured by scoring response of household heads to HFAIS questions. The questions were tested for their reliability in measuring food insecurity using Cronbach's Alpha $(\alpha)$ and the value was found to $80 \%$ indicating their consistency .The overall score of HFAIS was 27.

Socio-economic position (wealth index) which is an aggregate of thirteen variables such as presence of livestock, television, refrigerator, motorbike, bicycle, private house, internet centers, stationeries' shop, market center, hotel ownership, land ownership, furniture center, and vehicle. These variables were reduced to a single variable (wealth index) using principal component analysis (PCA) to produce a common factor score for each household. Accordingly, six area specific factor scores were obtained, correlation matrix $>0.3$, and total variance of $>60 \%$ were assumed during analysis. Then, the cumulative score of common factor scores was computed. Finally, wealth status of the households was divided as poor, medium, and rich for further analysis. In this study, permanent residence was defined as living for more than 6 months in the study area to be eligible for the study.

\section{Data quality control}

The study tools were pretested on five percent of the estimated sample size on similar setting outside the study area and all important corrections were made before the actual collection of the data. The data collectors and supervisors were trained for two days on the process of data collection. The supervisors closely supervised the 
data collection and the data were checked for completeness and consistency on the daily basis. The principal investigator carefully monitored the data collection process. Multivariable logistic regression analysis was carried out to control for all possible confounders.

\section{Data Management}

Three statistical software packages were used for data management. During the data collection, the data was checked every day for uniformity and completeness before data entry. The data was first entered into EPi-Info version 3.5.3 and the cleaned final data was then exported to SPSS version 20.0 for further analyses.

\section{Statistical analyses}

Simple and multiple logistic regressions were used to examine the association between food insecurity and the explanatory variables. From the simple regression models, predictive variables which were associated with the outcome at p-value less than 0.05 were selected for inclusion in the multiple logistic regression models. Statistical significance was set at $\mathrm{p}<0.050$ and $95 \%$ confidence interval.

Bivariate logistic regression model was used to assess the association between each independent variable and the dependent variable. All variables which had a p- value of less than 0.2 during bivariate analyses were included in multivariable logistic regression model to identify independent predictors of food insecurity. Multicollinearity test was carried out to see the correlation between the independent variables using standard error for categorical variables and variables with the stand error of greater than 2 were dropped from the analysis. HosmerLemshow significance test was used to test model fit at a p-value greater than 0.05. Multivariable analysis was used to control for all possible confounders and identify factors associated with household food insecurity using multivariable logistic regression.

\section{Operational definition:}

Food insecurity: Households with a food insecurity access scale (HFIAS) score through $2-27$ were considered to be food insecure. Those households with a (HFIAS) score $2-7,8-14$, and $15-27$ were categorized to be mildly, moderately, and severely food insecure respectively.

\section{Results}

\section{Socio-demographic and economic characteristics}

Among the total 309 household heads that participated in the study, 101 (32.7\%) were males. The mean age (SD) of household head was $34.39( \pm 2.3)$ years. The average family size was 5.6. Most of the household heads were Protestants (56.6\%) followed by Orthodox Christian (34.3\%). Majority of the respondents were Wolaita (88\%) in ethnicity. Ninety five percent of the study subjects were married Distribution of household heads by education revealed that $32.7 \%$ had diploma or more. Participants 'wealth status as determined by principal component analysis were $32 \%, 33.7 \%$ and $34.3 \%$ for poor, medium and rich households respectively using the thirteen asset ownership questions about their house hold wealth status. The average monthly household income was 2414.74 Ethiopian birr. Fifty two and thirteen percent of households reported trading and daily labor as their sources of income respectively. The average monthly food expenditure of the household was 1344.34 Ethiopian birr (Table 1). 
Table 1: Socio -demographic characteristics of study participants, Areka Town, Southern Ethiopia, March to April, 2015

\begin{tabular}{|c|c|c|c|}
\hline Variables & Categories & Frequency & Percent (\%) \\
\hline & Male & 101 & 32.7 \\
\hline Sex & Female & 208 & 67.3 \\
\hline \multirow{3}{*}{ Age } & 18-29 year & 101 & 32.9 \\
\hline & 30-50 year & 172 & 56 \\
\hline & $>50$ year & 34 & 11.1 \\
\hline \multirow[t]{3}{*}{ Family size } & $1-3$ & 51 & 16.5 \\
\hline & 4-6 & 177 & $\mathbf{5 7 . 3}$ \\
\hline & $7+$ & 81 & 26.2 \\
\hline \multirow[t]{5}{*}{ Ethnicity } & Wolaita & 272 & 88 \\
\hline & Oromo & 5 & 1.6 \\
\hline & Amhara & 13 & 4.2 \\
\hline & Gurage & 8 & 2.6 \\
\hline & Others & 11 & 3.6 \\
\hline \multirow[t]{4}{*}{ Religion } & Orthodox & 106 & 34.3 \\
\hline & Muslim & 8 & 2.6 \\
\hline & Protestant & 175 & 56.6 \\
\hline & Others & 20 & 6.5 \\
\hline \multirow[t]{4}{*}{ Marital status } & Married & 295 & 95.5 \\
\hline & Single & 4 & 1.3 \\
\hline & Separated & 4 & 1.3 \\
\hline & Widowed/divorced & 6 & 1.9 \\
\hline \multirow[t]{5}{*}{ Sources of income } & Salary & 132 & 42.1 \\
\hline & Trading & 161 & 52.1 \\
\hline & Daily work & 39 & 12.6 \\
\hline & Agriculture & 41 & 13.3 \\
\hline & Others & 23 & 7.4 \\
\hline \multirow[t]{4}{*}{ Educational status } & Illiterate & 72 & 23.3 \\
\hline & Elementary & 79 & 25.6 \\
\hline & High school & 57 & 18.4 \\
\hline & Diploma and above & 101 & 32.7 \\
\hline \multirow[t]{3}{*}{ Monthly HH income } & $<600$ ЕTB & 18 & 5.8 \\
\hline & 600-2000 ЕТВ & 122 & 39.5 \\
\hline & $>2000$ ETB & 269 & 54.7 \\
\hline \multirow[t]{3}{*}{ Wealth index } & Poor & 99 & 32 \\
\hline & Medium & 104 & 33.7 \\
\hline & Rich & 106 & 34.3 \\
\hline \multirow{3}{*}{$\begin{array}{l}\text { Monthly HH food } \\
\text { expenditure }\end{array}$} & $<500$ ETB & 35 & 11.3 \\
\hline & 500-1500 ЕТВ & 156 & 50.5 \\
\hline & $>1500 \quad$ ETB & 118 & 38.2 \\
\hline
\end{tabular}

Prevalence of household food insecurity

Affirmative response to worrying about food inaccessibility was given by 124 households (40\%). 189(61\%) households reported that they ate limited variety of food, 137 (44\%) affirmed to eating smaller meal portions, whereas $115(37 \%)$ households gave affirmative responses to eating fewer meals. The proportion of affirmative responses given for going to bed hungry and eating no food over the whole day were $4(1.3 \%)$ and $2(0.6 \%)$ respectively (Table 2). 
Table 2: Percentage distribution of respondents' responses to the HFIAS questionnaires, Areka Town, Southern Ethiopia, March to April, 2015

\begin{tabular}{|c|c|c|c|c|c|}
\hline Indicator & $\begin{array}{l}\text { No } \\
N(\%)\end{array}$ & $\begin{array}{l}\text { Total } \\
\text { N }(\%)\end{array}$ & $\begin{array}{l}\text { Rarely } \\
\text { N }(\%)\end{array}$ & $\begin{array}{l}\text { Some times } \\
\mathrm{N}(\%)\end{array}$ & $\begin{array}{l}\text { Often } \\
\text { N (\%) }\end{array}$ \\
\hline Worry about food shortage & $185(60)$ & $124(40)$ & $45(14.6)$ & $65(210$ & $14(4.5)$ \\
\hline Not able to eat foods they preferred & $125(41)$ & $184(59)$ & $52(16.8)$ & $94(30.4)$ & $38(12.3)$ \\
\hline Eating just a few kinds of foods & $120(39)$ & $189(61)$ & $66(21.4)$ & $89(28.8)$ & $34(11)$ \\
\hline Eating foods that are not preferred & $152(49)$ & $157(51)$ & $43(14)$ & $82(26.5)$ & $32(10.5)$ \\
\hline Household members eat a smaller meal & $172(56)$ & $137(44)$ & $51(16.5)$ & $65(21)$ & $21(6.8)$ \\
\hline $\begin{array}{l}\text { Household members ate fewer meals in } \\
\text { a day }\end{array}$ & $194(63)$ & $115(37)$ & $43(14)$ & $56(18)$ & $16(5)$ \\
\hline No food at all in the household & $298(96.4)$ & $11(3.6)$ & $5(1.6)$ & $5(1.6)$ & $1(0.3)$ \\
\hline $\begin{array}{l}\text { Household members went to sleep } \\
\text { hungry }\end{array}$ & $305(98.7)$ & $4(1.3)$ & $(1.3)$ & $0(0)$ & $0(0)$ \\
\hline $\begin{array}{l}\text { Household members went a whole day } \\
\text { \& night without eating }\end{array}$ & $307(99.4)$ & $2(0.6)$ & $1(0.3)$ & $1(0.3)$ & $0(0)$ \\
\hline
\end{tabular}

The mean HFIAS score of the sample households was 5.5. A total of $215[69.6 \%, 95 \% \mathrm{CI}=(64.1,75.2)]$ households had a score from 2 to 27 , which indicates that they were food insecure. Household food insecurity was further categorized based on its severity. Accordingly, 34.3\%, 95\% CI $=(29.4,39.8)], 31.7 \%, 95 \% \mathrm{CI}=(26.1$, $37.0)]$, and $3.6 \%, 95 \% \mathrm{CI}=(1.9,5.8)]$ of the households were found to be mildly, moderately and severely food insecure respectively (Figure 1).

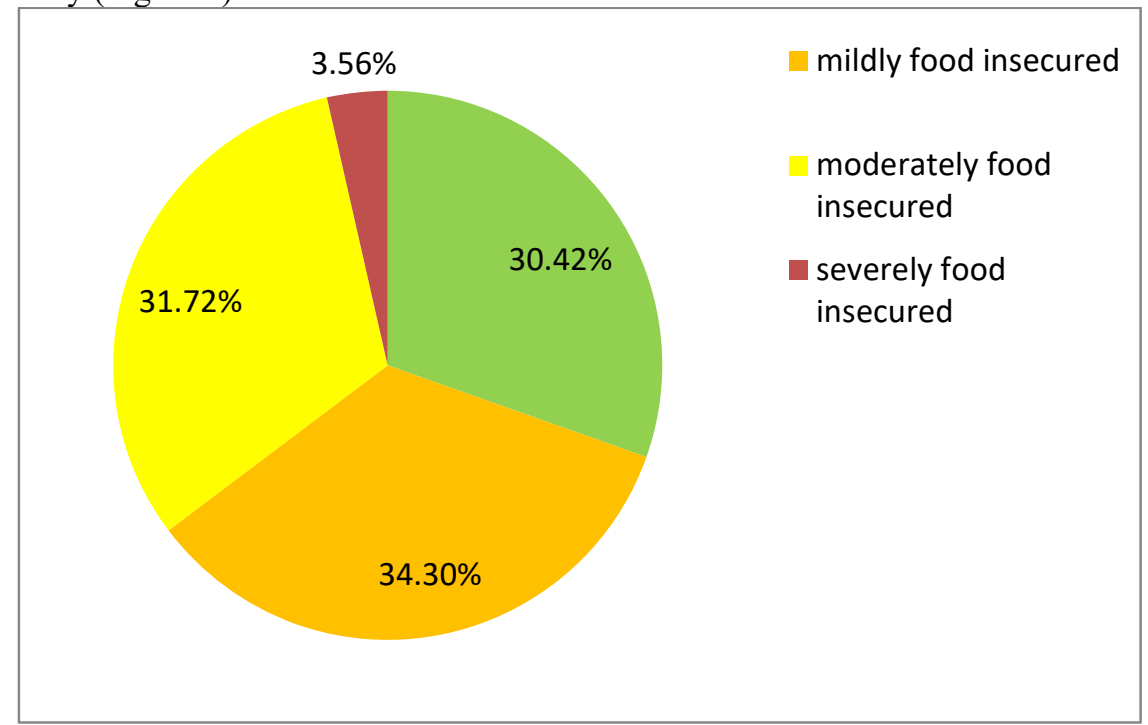

Figure 1: Prevalence of household food insecurity, Areka Town, Southern Ethiopia, March to April, 2015

$$
(\mathbf{N}=309)
$$

Factors associated with household food insecurity

In the multivariable logistic regression model, household food insecurity was significantly associated with lack of formal education by household head $[(\mathrm{AOR}=4.70,95 \% \mathrm{CI}=(1.82,12.12)]$, poor household wealth index $[(\mathrm{AOR}=3.13,95 \% \mathrm{CI}=(1.42,6.91)$, households monthly food expenditure less than 500ETB $[(\mathrm{AOR}=2.70,95 \%$ $\mathrm{CI}=(1.49,4.91)]$, and household heads aged 50 years and above $[(\mathrm{AOR}=2.11,95 \% \mathrm{CI}=(1.12,3.95)]$ (Table $3)$. 
Table 3: Bivariate and Multivariable regression analysis for selected household characteristics, Areka Town, Southern Ethiopia, March to April, 2015

\begin{tabular}{|c|c|c|c|c|c|}
\hline \multirow[t]{2}{*}{ Variables } & \multirow[t]{2}{*}{ Categories } & \multicolumn{2}{|c|}{ Food security status } & \multirow{2}{*}{$\begin{array}{l}\text { COR } \quad(95 \% \\
\text { CI })\end{array}$} & \multirow{2}{*}{$\begin{array}{l}\text { AOR } \quad(95 \% \\
\text { CI) }\end{array}$} \\
\hline & & $\begin{array}{l}\text { Food } \\
\text { insecure } \\
\text { Number } \\
(\%) \\
\end{array}$ & $\begin{array}{l}\text { Food } \\
\text { secure } \\
\text { Number } \\
(\%) \\
\end{array}$ & & \\
\hline \multirow{3}{*}{$\begin{array}{l}\text { Age of household } \\
\text { head }\end{array}$} & 18-29 years & $64(63 \%)$ & $37(37 \%)$ & 1.00 & \\
\hline & $30-49$ years & $123(71.5 \%)$ & $49(28.5 \%)$ & $\begin{array}{l}1.45 \\
(0.86,2.45)\end{array}$ & $\begin{array}{l}1.57 \\
(0.53,4.67)\end{array}$ \\
\hline & $\geq 50$ year $\mathrm{s}$ & $26(76.5 \%)$ & $8(23.5 \%)$ & $\begin{array}{l}1.88 \\
(0.77,4.57)\end{array}$ & $\begin{array}{l}2.11 \quad(1.12, \\
3.95)^{*}\end{array}$ \\
\hline \multirow[t]{2}{*}{$\begin{array}{l}\text { Household's daily } \\
\text { source of income }\end{array}$} & Daily worker & $33(84.6 \%)$ & $6(15.4 \%)$ & $\begin{array}{l}2.66 \\
(1.07,6.58)\end{array}$ & $0.59(0.2,1.73)$ \\
\hline & Not daily worker & $182(67.4 \%)$ & $88(32.6 \%)$ & 1.00 & \\
\hline \multirow[t]{3}{*}{$\begin{array}{l}\text { Household } \\
\text { index }\end{array}$} & Poor & $84(85 \%)$ & $15(15 \%)$ & $\begin{array}{l}4.80 \\
(2.45,9.40)\end{array}$ & $\begin{array}{l}3.13 \quad(1.42, \\
6.91)^{* *}\end{array}$ \\
\hline & Medium & $74(71 \%)$ & $30(29 \%)$ & $\begin{array}{l}2.12 \\
(1.20,3.75)\end{array}$ & $\begin{array}{l}1.73 \\
(0.91,3.28)\end{array}$ \\
\hline & Rich (ref.) & $57(53.7 \%)$ & $49(46.3 \%)$ & 1.00 & 1.00 \\
\hline \multirow[t]{3}{*}{$\begin{array}{l}\text { Household's non - } \\
\text { food expenditure }\end{array}$} & $<200$ ETB & $78(88 \%)$ & $11(12 \%)$ & $\begin{array}{l}6.84 \\
(3.28,14.24) \\
\end{array}$ & $\begin{array}{l}1.60 \\
(0.58,4.43)\end{array}$ \\
\hline & 200-499 ETB & $79(74 \%)$ & $28(26 \%)$ & $\begin{array}{l}2.72 \\
(1.54,4.81) \\
\end{array}$ & $\begin{array}{l}1.48 \\
(0.73,3.03)\end{array}$ \\
\hline & $\geq 500 \mathrm{ETB}$ & $56(51 \%)$ & $54(49 \%)$ & 1.00 & \\
\hline \multirow[t]{4}{*}{$\begin{array}{l}\text { Household head 's } \\
\text { educational status }\end{array}$} & $\begin{array}{l}\text { Have no formal } \\
\text { education }\end{array}$ & $65(90.3 \%)$ & $7(9.7 \%)$ & $\begin{array}{l}9.10 \\
(3.81,21.77)\end{array}$ & $\begin{array}{l}4.70 \quad(1.82, \\
2.12)^{* *} \quad\end{array}$ \\
\hline & Elementary & $60(76 \%)$ & $19(24 \%)$ & $\begin{array}{l}3.10 \\
(1.62,5.91)\end{array}$ & $\begin{array}{l}1.82 \\
(0.91,3.82)\end{array}$ \\
\hline & High school & $39(68.5 \%)$ & $18(31.5 \%)$ & $\begin{array}{l}2.12 \\
(1.07,4.20)\end{array}$ & $\begin{array}{l}1.48 \\
(0.70,3.17)\end{array}$ \\
\hline & $\begin{array}{l}\text { Diploma and } \\
\text { above }\end{array}$ & $51(50.5 \%)$ & $50(49.5 \%)$ & 1.00 & 1.00 \\
\hline \multirow[t]{3}{*}{$\begin{array}{l}\text { Household } \\
\text { expenditure }\end{array}$} & $<500$ ETB & $33(94.3 \%)$ & $2(5.7 \%)$ & $\begin{array}{l}17.70 \\
(3.92,74.40) \\
\end{array}$ & $\begin{array}{l}6.90 \\
(1.45,32.9)^{*} \\
\end{array}$ \\
\hline & 500-1500 ETB & $124(79.5 \%)$ & $32(20.5 \%)$ & $\begin{array}{l}4.10 \\
(2.40,6.81) \\
\end{array}$ & $\begin{array}{l}2.70 \\
(1.48,4.91)^{* *}\end{array}$ \\
\hline & $>1500+\mathrm{ETB}$ & $58(49 \%)$ & $60(51 \%)$ & 1.00 & 1.00 \\
\hline \multirow[t]{3}{*}{ Household income } & $<600$ ETB & $17(94.4 \%)$ & $1(5.6 \%)$ & $\begin{array}{l}13.56 \\
(1.76,104.26) \\
\end{array}$ & $\begin{array}{l}1.30 \\
(0.51,3.26) \\
\end{array}$ \\
\hline & 600-1999 ЕТВ & $104(85.3 \%)$ & $18(14.7 \%)$ & $\begin{array}{l}4.61 \\
(2.57,8.28) \\
\end{array}$ & $\begin{array}{l}1.2 \\
(0.05,27.04)\end{array}$ \\
\hline & $\geq 2000 \mathrm{ETB}$ & $94(55.6 \%)$ & $75(44.4 \%)$ & 1.00 & \\
\hline
\end{tabular}

\section{Discussion}

This study indicated the prevalence of household food insecurity to be $70 \%$, of which $34.3 \%$ of the households were mildly food insecure and $31.7 \%$ of households were moderately food insecure, while very few $3.6 \%$ of them were severely food insecure. Household food insecurity was significantly associated with household heads that did not have formal education, households with poor wealth index, households with monthly food expenditure less ETB500, and household heads aged over 50 years.

This study reports higher prevalence of household food insecurity. The result was much higher than the national food insecurity (37.1\%) as estimated by world FAO in 2011-2013 [4].This higher level of food insecurity could be attributed to seasonal variation in household food security status which is often higher in the months from February to April in Ethiopian context. It might also be explained by eating fewer and smaller meals among households due to monotonous diet and less diversified food items. However, the result was in accordance with other similar studies conducted in different parts of Ethiopia including the study setting[6, $20-21]$ and other urban communities of low income countries $[10,14,18]$. 
Households headed by household heads who did not have formal education were more likely to be food insecure compared with their counter parts. This might be due to the fact that uneducated household heads might not able to satisfy the food needs of their families due to shortage in the food expenditure and lower awareness to dietary diversification as a result of lack of health education. This finding was consistent with other studies conducted in Ethiopia, Addis Ababa [6-7, 21] and study conducted in India [10, 14].

According to this survey, poor households as explained by low wealth index were more likely to be food insecure. This might be explained by the fact that poor urban households might have no /or single source of income that might not enable them to purchase adequate foods that can satisfy the required needs of their household members due to pronounced poverty. This finding was consistent with other previous findings in SSA countries including Ethiopia [15,17,19,21- 22].

Household's monthly expenditure on food was also found to be significantly associated with household food insecurity. Those households which spend between ETB 500 to ETB 1500 on a monthly basis for their food consumption were more likely to be food insecure as compared with their counter parts. This could be attributed to low purchasing power of the households with low income to timely respond to the food needs of their families on regular basis. This finding was in agreement with study conducted in South Africa [22].

This study revealed that the age of household head was significantly associated with household food insecurity. Households headed by heads more than 50 years of age were more likely to be food insecure as compared to their counter parts. This could be due to the fact that older household heads were not used to actively engage in different activities to generate household income compared with their counterparts and they might not have productive household members and often live on pension. This finding is in line with previous studies done in Ethiopia and other countries [16, 20].

\section{Conclusion}

The prevalence of urban household food insecurity was found to be high in the study setting and associated with being in the older age group of household heads and lack of formal education by the household head, household poverty, and less monthly household expenditure for food consumption. Thus, it is essential that an integrated feasible urban food security interventions should be emphasized at all levels by all relevant stakeholders targeting the urban poor households to curb urban household food insecurity.

$\begin{array}{ll}\text { List of Abbreviations } \\ \text { AOR } & \text { Adjusted Odd Ratio } \\ \text { COR } & \text { Crude Odd Ratio } \\ \text { ETB } & \text { Ethiopian Birr } \\ \text { HH } & \text { House Hold } \\ \text { HH' } & \text { House Hold Head } \\ \text { OR } & \text { Odds Ratio } \\ \text { SD } & \text { Standard Deviation } \\ \text { SNNPR } & \text { Southern Nation Nationalities and Peoples Region } \\ \text { SRS } & \text { Simple Random Sampling } \\ \text { SSA } & \text { Sub Saharan Africa } \\ \text { TEM } & \text { Technical Error of Measurements } \\ \text { WHO } & \text { World Health Organization }\end{array}$

\section{Declarations}

Ethics approval and consent to participate

Ethical clearance was obtained from Research and Ethical Committee of Wolaita Sodo University, School of Public Health. Informed written consent was obtained from each study subjects (household heads), and the purpose of the study was explained to the respondents in advance. Confidentiality of the information and privacy of the respondents was maintained. During the data collection, each study participant (household heads) was informed that their participation was voluntary, and that they could quit from the study any time, even after the interview has started.

Consent for publication

Not applicable

\section{Availability of data and material}

The datasets during and/or analyzed during the current study are available from the corresponding author on reasonable request. 


\section{Competing interests}

The authors declare that this study is free of any competing financial and non-financial interests.

\section{Funding}

Not applicable

\section{Authors' contributions}

HS: has taken a lead role from inception of the research idea up to its final stage including data analysis and write up of the manuscript. GE: participated in the planning of the study by giving constructive comments throughout the stages of the research work including the development of the manuscript. WP: participated in the planning of the study by giving constructive comments and ideas and involved in data analysis and write up of the manuscript. All authors read and approved the final manuscript. TY and MT were involved in the analysis and interpretation of findings and participated in the analysis, interpretation and writing. All authors read and approved the final version of the manuscript.

\section{Acknowledgements}

Areka town health office, the supervisors, data collectors, study participants, Wolaita Sodo University, College of Health Sciences, and School of Public Health.

\section{Authors' information}

Habte Samuel: Maternal and child health \& nutrition service core process, Regional Health Bureau, Southern nations, nationalities and people, Ethiopia.

Gudina Egata: Public Health, College of Health and Medical Sciences, Haramaya University, Ethiopia.

Wondimagegn Paulos: School of Public Health, Wolaita Sodo University, Ethiopia.

TesfahunYonas Bogale: College of Health Sciences and Medicine, School of Public Health, Wolaita Sodo University, Ethiopia.

Minyahil Tadesse Boltena: Armauer Hansen Research Institute, Ministry of Health, Ethiopia.

\section{References}

1. The State of Food Insecurity: Report 2002 Food and agricultural organization in Rome, Italy. FOA (2002). Food and Agricultural Organization.

2. Global food security index. An annual measure of the state of global food security. 2013, the Economist Intelligence Unit Limited 2013.

3. FISHER, C.T.w.B.B.a.S., Urban poverty, food security and climate change. 2013.

4. The state of Food Insecurity in the world. The multiple dimensions of food security. 2013: FAO, IFAD and WFP Rome.

5. Ethiopia's Progress towards Eradicating Poverty: An Interim Report on Poverty Analysis Study 2012: Addis Ababa.

6. Gebre, G.G., Determinants of Food Insecurity among Households in Addis Ababa City, Ethiopia. 2012. 10(2): p. 159-173.

7. Tesfaye Birhane, S.S., Seifu Hagos and Katia Sarla Mohindra, Urban food insecurity in the context of high food prices: a community based cross sectional study in Addis Ababa, Ethiopia. BMC Public Health, 2014. 14: p. 1-8.

8. NICEF/WFP (2009). Summary of Food security and vulnerability in selected urban centers of Ethiopia. Addis Ababa, Ethiopia.

9. Muhammad Khalid Bashir, S. S., and Ram Pandit (2012). Livestock and Rural Household Food Security: The Case of Small Farmers of the Punjab, Pakistan Working Paper 1207 School of Agricultural and Resource Economics http://www.are.uwa.edu.au

10. Palanivel Chinnakali1, R.P.U., DeepaShokeen, Kavita Singh, Manpreet Kaur, and A.G. Arvind K. Singh, Kapil Yadav, Chandrakant S. Pandav, Prevalence of Household-level Food Insecurity and Its Determinants in an Urban Resettlement Colony in North India. J HEALTH POPUL NUTR, 2014. 32(2): p. 227-236.

11. Central Statistical Agency [Ethiopia] and ICF Inte rnational. 2012. Ethiopia Demographic and Health Survey 2011. Addis Ababa, Ethiopia and Calverton, Maryland, USA: Central Statistical Agency and ICF International.

12. Wolaita Zone central statistics agency. 2013.

13. Coates J, Swindale A, Bilinsky P. Household Food Insecurity Access Scale (HFIAS) forMeasurement of Household Food Access: Indicator Guide (v. 3). .Washington, D.C.Washington, D.C.: Food and Nutrition Technical Assistance Project, Academy forEducational Development, 2007. Available at:http://www.fao.org/fileadmin/user_upload/eufao-fsi4dm/doc-training/hfias.pdf. Accessed 10 February 2017. 
14. Md.Ismail, Status of food security in some selected villages in Malda District. Social science, 2012.

15. MeenakshiJha, A.A.M.N., Experiential household food insecurity in an urban underserved slum of North India. Springer Science Business Media B.V. \& International Society for Plant Pathology, 2009.

16. A., O.O., Assessment of Households' Food Access and Food Insecurity in Urban Nigeria: A Case Study of Lagos Metropolis. Global Journal of HUMAN-SOCIAL SCIENCE: E Economics, 2014. 14.

17. Vulnerability to Food Insecurity in Urban Slums: Experiences from Nairobi, Kenya. Urban Health, 2014.

18. Muteba, P.L.a.D., Characteristics of Urban Food insecurity: The Case of Kinshasa African Review of Economics and Finance 2011. 3.

19. James O. Owino, G.J.C., Christopher K. Saina, Florence. A. Murgor, the Coping Strategies Adapted by Urban Poor to Food Insecurity in Eldoret Municipality, Kenya. Journal of Emerging Trends in Economics and Management Sciences (JETEMS), 2013. 4(2): p. 196-202.

20. WorkuEndale, Z.B.M., AzebAtinafu, and Akilew Awoke Adane, Food Insecurity in Farta District, Northwest Ethiopia: a community based cross-sectional study. 2014. 7: p. 130.

21. Tebeje, B.G.G.R.M., Rural Households Food Security and Livelihood Strategies IJRESS, 2014.

22. Napier, C.E., Poverty, household food insecurity and nutrition: coping strategies in aninformal settlement in the vaal triangle, south Africa. Public health, 2006. 120(9): p. 795-804 